\title{
Erratum to: Daily Forecasting of Dam Water Levels: Comparing a Support Vector Machine (SVM) Model With Adaptive Neuro Fuzzy Inference System (ANFIS)
}

\author{
Afiq Hipni • Ahmed El-shafie • Ali Najah • \\ Othman Abdul Karim • Aini Hussain • \\ Muhammad Mukhlisin
}

Published online: 1 August 2013

(C) Springer Science+Business Media Dordrecht 2013

\section{Erratum to: Water Resour Manage DOI 10.1007/s11269-013-0382-4}

The original version of this article unfortunately contained a mistake in the affiliation. The correct presentation of the affiliation should be like of the below.

The online version of the original article can be found at http://dx.doi.org/10.1007/s11269-013-0382-4.

A. Hipni · A. El-shafie · O. A. Karim • A. Hussain • M. Mukhlisin

Department of Civil and Structural Engineering, University Kebangsaan Malaysia,

Bangi, Selangor, Malaysia

A. Najah $(\bowtie)$

Department of Engineering Science, Universiti Malaysia Terengganu,

Kuala Terengganu, Terengganu, Malaysia

e-mail: ali_najah@ymail.com

M. Mukhlisin

Department of Civil Engineering, Polytechnic Negeri Semarang, Semarang, Indonesia 